\title{
Subjective experiences of older adults in poverty in urban China and the role of social policy
}

\author{
Yan-Yan Chena, Robert Walkerb and Liu Honga
}

\begin{abstract}
This study establishes an evidence base regarding the experiences of older adults living in poverty in Beijing. Given the factors that shape the lives of low-income older adults, the findings are relevant for many middle and low-income countries. Based on a series of in-depth interviews conducted with government officials and low-income older adults in Beijing, the study finds that poverty manifests as cumulative stress arising from four sources: financial strain, poor health, care burden, and poverty-related shame. This stress is attributable to the co-existence of individual and structural factors that reflect the framing of anti-poverty policies in China.
\end{abstract}

Key Words: Older adult poverty; stress; multi-dimensionality of poverty; policy shaping; urban China

\footnotetext{
a Department of Social Work, Fudan University, Shanghai City, P.R. China;

b.Department of Social Policy and Intervention, University of Oxford, Oxford, UK
} 


\section{Introduction}

China is currently confronted by an aging population, persistent poverty and an embryonic social protection system (Barrientos, 2011). While estimates of the Chinese population living in poverty are difficult to obtain, Dibao (the Minimum Living Allowance) may be used as a measure of urban poverty in absolute terms. Statistics from the Ministry of Civil Affairs of China indicate that approximately 3.4 million older adults in urban areas receive Dibao in 2012, one in six of all Dibao recipients. While China is unique in the scale of the problems it faces, many middle income and developing countries share a rapid demographic change, new family forms, and shifting value systems. Given these trends, China must determine a sustainable balance between growth-led development and changing social needs. Despite substantial development in China, many older citizens who have minimally benefited from economic growth are confronted with precarious circumstances. Although pushing for an expanded social protection system to meet the needs of this vulnerable population, the Chinese government lacks an understanding of the needs of those that they are expected to serve.

Many structural reasons account for this gap in policy for older adults living in poverty. Political issues seen as more pressing often take preference, the scale of the problem and its resource implications make it difficult to establish a clear solution, and the lack of voice of those most affected reduce political pressure for action. At a policy level, the government demonstrates a lack of understanding of the complex reality of older adults experiencing a combination of reduced income, declining health, increasing needs for care, coupled with the care responsibilities many older adults assume themselves as parents and spouses. These issues are complicated by declining traditional informal support systems in the context of rapid urbanisation. This article seeks to establish an evidence base regarding poverty among older adults in urban China, while retaining a broader relevance for many middle and low-income countries where the lives of older adults are shaped by similar factors. Based on a series of 
repeated in-depth qualitative interviews with government officials and low-income older adults in Beijing, China, this study highlights that poverty is experienced by older adults as cumulative stress arising from the co-existence of individual and structural factors, the latter often reflected in the framing of social policy.

\section{Poverty among older adults in China}

Poverty has traditionally been defined as a condition in which one cannot maintain the proper functioning of body (Rowntree, 1901), or, a condition of lacking income. Since the seminal works of Townsend (1979), Streeten (1981) and Sen (1981), poverty has been understood as a multifaceted phenomenon, with its specific definition varying according to the socio-demographics of those affected. The existing body of qualitative literature on the experiences of older adults living in poverty echoes this pluralistic definition, acknowledging that poverty cannot be solely defined in monetary and material terms. For instance, poverty has been found to be related to intimate relations, friendships, emotion and spirituality in different cultures (Black \& Rubinstein, 2000; Lloyd-Sherlock \& Locke, 2008).

Poverty among older adults is characterised not only by its multidimensionality, but by its persistence and sensitivity to familial form and relationships. Persistence of poverty among older adults in China reflects exclusion from the labour market after retirement, and therefore, a limited ability to change life circumstances. Moreover, as a number of qualitative studies confirm, the financial circumstances of an elder are often dependent on the extent to which household income is pooled (Schröder-Butterfill, 2004; Vera-Sanso, 2012).

The nature and extent of poverty among urban elders partly reflects the shift from a universal model of welfare provision to the residual one that accompanied the market transformation of China (Guan, 2003). This 'low-level and narrow-coverage' social welfare system meant that provision no longer matched social need. In 2007, the Ministry of Civil Affairs proposed moving to a 'modest universal model'. In 
response, the Beijing city authorities introduced a series of anti-poverty measures to complement Dibao, particularly to support older adults. These measures include a pension program referred to as a Welfare Pension designed to support those not covered by other retiree pension plans, medical insurance called 'One-Old-One-Young' (OOOY) available to older adults without other health insurance coverage, and a home care allowance for those requiring support from a family caregiver. (see Table 1). These measures introduced some degree of universalism for those elders not previously covered through the minimal social insurance, but they still held to the principle that the state should only intervene when the market and the family systems fail (Wilensky \& Lebeaux, 1965).

\section{[Insert table 1 around here]}

Studies of poverty among older adults in China (e.g., Saunders \& Sun, 2006; Qiao, Zhang \& Sun, 2006) have focused on objective indicators, such as financial security, housing, health, social exclusion, and social status. Largely absent in debates about poverty among older adults in China, and to a lesser extent elsewhere, have been the voices and knowledge of those directly experiencing poverty. Despite a few qualitative studies on older adults elsewhere (e.g. Black \& Rubinstein, 2000; Lombard \& Kruger, 2009), little is known about this subjective experience in the Chinese context.

\section{Theoretical framework and methodology}

In this study, poverty among older adults is conceptualised as the consequences of a shortage of required resources that results in multidimensional disadvantages. This conceptualisation blends critical gerontology with stress theory. Critical gerontology rejects the notion of aging as a problem of dependency. It problematises dependency by recognising existing constraints experienced by low-income older adults as being structurally imposed by a society. Most notable is the role of the state in determining how resources are allocated via the market and through social welfare systems (Estes, 
1979). To elucidate how the experience of urban older adults is shaped by social policy, the language of stress and stressors is adopted.

Stress can be understood as an internal state arising from the imbalance between an environmental demand (the stressor) and a person's ability to respond appropriately (Aldwin, 2007). In the context of poverty, stress is a crisis or long-term strain caused by a shortfall between socially defined necessary resources and personally experienced needs. Typically, the level of stress relates to the degree of misfit between resources and demands, and how this gap is perceived and appraised (Lazarus, 1991). This approach places the individual experiencing stress at the heart of the enquiry (Jones, Bright, \& Clow, 2001).

This study comprised 17 elders selected from five communities in Beijing, China, whose disposable income is less than 50 per cent of the per capita mean income of the city (1114 Yuan per month in 2009). Each person was interviewed twice. The first round of interviews was conducted in September and December, 2009 and the second in November, 2010. Fifteen participants were women and two were men; eight were aged between 60 and 69, five between 70 and 79, and four were 80 or over. Six respondents had received no diploma or degree, two had a high school diploma, and one had a college degree. A life story approach was adopted for the interview process, focusing on accounts of events, experiences, thoughts, and feelings regarding poverty, and on manifestations and interpretation of related stress. The interviews averaged 60 minutes in length and were audio recorded and transcribed for analysis. Five government officials in charge of the communities were interviewed within the same time frame. These respondents were each interviewed on two occasions regarding their perceptions of the relevant social policies.

Thematic analysis was completed using NVivo 8.0 software. Interpretation of data reflected the theoretical perspectives of stress and critical gerontology described above, and was guided by each respondent's subjective reference framework (Atkinson, 1998). The research was conducted in accordance with proper ethical 
procedures and principles (Neuman, 2005).

\section{Findings: multiple sources of stress}

Based on the qualitative data, participants of this study experienced poverty as four forms of cumulative stress attributable to cost of daily living, poor health, care responsibilities, and poverty-related shame.

\section{Cost of daily living}

Each respondent encountered extreme difficulties in obtaining basic necessities of living and felt stressed by having to prioritise between essentials. Most respondents had only worked in government-run welfare enterprises or as temporary workers, and were therefore receiving only a modest pension. Female respondents often had no pension or personal savings, as they had not worked since marriage. They found it very difficult to meet every day needs, with resources reported as being 'tight', and life 'quite tense'. Some respondents received hardly any financial support from their adult children. The financial circumstances of childless elders were particularly precarious. While the participants managed to secure adequate food, other essential costs such as consulting a doctor were difficult to cover.

\section{Poor health}

Despite the widely accepted principle that people with the same health care needs should be treated equally (Morris, Sutton \& Gravelle, 2005), it is hard to ensure this equality for all older adults. People in poverty are more likely to be struck by serious and chronic health conditions and to receive a lower level of care when formal treatment is sought (Xie, 2011). Poor health is a major cause of poverty for older adults in China and profoundly shapes their lives (Wang, 2010). Table 2 shows age, health condition and medical history of the respondents. A number were bedbound, one was suffering from the advanced cancer, and others were variously afflicted by neck arthritis, blurred vision, dizziness, and mild heart disease. 


\section{[Insert Table 2 about here]}

The stress arising from poor health was exacerbated by the cost of treatment. For those who were insured under the OOOY program, 60 per cent of their medical costs were covered, but the remaining out-of-pocket sum often proved daunting. The respondents frequently could not afford to follow medical advice, which impeded their recovery and rehabilitation. One respondent, who had recently been discharged from the hospital, explained the dilemma. 'The doctor asked me to have a good rest. How do I rest? I have to make a living. I have to work'. The respondents were fully aware of the dangers of delaying treatment, but had no choice but to ignore doctors' advice. Indeed, one of the male participants gravely described potential health threats. 'My whole family will be destroyed if I develop a serious disease'. This knowledge added to the pain and discomfort caused by chronic illness, fuelled fear and uncertainty, and ultimately contributed to a sense of helplessness.

\section{Care responsibilities}

Many of the participants still cared for their extended family members, including adult children. Caregiver responsibilities further strained their meagre resources, and became a source of stress. However, the respondents found no alternative but to support their offspring, most of whom were also poor, with no or low incomes due to disability, limited education, or criminal records that limited employment prospects.

The assumption that financial responsibility always passes naturally from one generation to the next did not always hold for the respondents. One, for example, who had been a widow for two decades, supported a household of four on a pension of just 900 Yuan. Her eldest son had passed away, and the two remaining sons lived with her. Neither was employed; one had a criminal record, and the other was divorced with a young daughter. Both sons received Dibao allowance. While the former did not contribute financially, the latter contributed only 200 Yuan per month, which was insufficient to cover his and his daughter's living expenses. The strain on the mother 
was clear. 'I have to support the whole family, and also have to parent my granddaughter, you can't imagine....'

Several respondents had adult children with disabilities, which meant that proactive parenting continued into old age. For example, one respondent, her son, daughter-in-law, grandson, and eldest daughter lived together. The son, daughter, and daughter-in-law all had disabilities; the former two had brain injuries and consequently paralysis; the daughter-in-law experienced difficulty walking, but still managed to hold down a job working nights. This respondent saved the 400 Yuan that her son contributed each month as insurance against his ongoing health expenses. Similarly, the 500 Yuan that she received from her daughter mostly paid for her medical needs. Meanwhile, her grandson was in middle school, which she saw as ' $a$ time to spend money'. The five-person household subsisted on her monthly 1700 Yuan pension. She expressed that life seemed overwhelming at times. 'Sometimes I feel upset, so tired when doing much housework. Well, I would rather die! ... [If so] I'd never care for them!'

Supporting the costs of higher education for children represented another financial drain. One respondent, having no pension and receiving Dibao, had managed to supplement the local government's grant for his daughter's university study by riding a rickshaw tricycle. However, during her second year, her public funding was cut down to 1,000 Yuan. Moreover, his daughter subsequently developed hyperthyroidism. The cost of medical treatment pushed the family deeply into debt. His anxiety was laced with bitterness: 'Anyway, we'll try our best to let the child finish her studies. ...We can eat whatever poor food and wear whatever worn-out clothes'.

Some participants had to juggle multiple care needs. For instance, one participant had to provide direct care for the children of her two sons who lived in the same apartment, while simultaneously looking after her husband who suffered from serious mental illness. She had to manage the combined financial demands of two grandsons 
and her husband's medical expenses. She worked long hours collecting and selling scraps. Although she has a 700 Yuan pension, and her husband had 2500 Yuan plus medical insurance that covered $90 \%$ of the costs, medicine and nursing care were still overwhelming. Her husband's unstable mental state and sometimes violent behaviours added to the family's dire situation. She commented that 'a good family has been destroyed', and thought of herself as 'rather pitiful'.

The need to support and care for families dominated the lives of many of the participants. Physically and emotionally exhausted, their burden was further exacerbated by additional financial demands. Stress was often manifested as anxiety, fatigue, despair, and helplessness.

\section{Poverty-related shame}

Another source of stress was the shame associated with poverty. Shame was evident from the comparisons that the elders made between themselves and 'others', especially from their use of the word 'they'. Several compared their circumstances directly with those of relatives. 'Look at my house, dilapidated and dirty. They (my relatives) are all better than me'. Neighbours constituted another reference group. Some participants felt that their identity of a Dibao or Welfare Pension recipient set them apart from peers in a sharply hurtful way. One participant referred to his Dibao recipient identity as an isolating experience. 'In my neighbourhood, I'm one of a kind. They are all retirees.'

The respondents not only believed themselves to be 'worse off' in the sense of lacking possessions, missing out on entertainment, and providing inadequately for their children; they also expressed the belief that they were socially and morally inferior. This led some to avoid social contact and to lower their expectations in life. One cancer sufferer had heard of a patients' anti-cancer club, but had not participated because her economic circumstances 'were worse than others'. A father who hoped higher education would lift his daughter from poverty was nevertheless afraid that 
their status would prevent her from securing a job.

The participants frequently expressed that they were despised because of poverty. One respondent, referring to her experience at a charitable medical consultation event, reported that paramedics refused to perform check-ups for her. She took the experience to heart, saying, 'I don't have money, so they belittle me'. She reported to have experienced this 'time and again'. Sometimes, the respondents felt disowned by their extended family members. When relatives believe that they were only 'to ask for money', the common reaction among the respondents was to withdraw from social contact in order not to be belittled.

Generally, the participants claimed to avoid talking about their financial circumstances, which was embarrassing and shameful. One woman explained that she 'would rather say I have something and not tell others I am poor. Even if you talk about poverty, nobody cares! They will look down upon you!' Another admitted that she would never ask for help. 'Seek help? Tell them I am poor? No. [If I do that]) I will be belittled.' Participants tended to remain in their homes, feeling 'too shameful to be seen by the neighbours'. While shame was externally imposed by family, neighbours, and society at large, it was nevertheless internalised. The elders saw themselves as being at the bottom of society and felt themselves to be 'inferiors', akin to being 'beggars'.

In sum, the respondents experienced poverty as four types of stress resulting from: cost of daily living; poor health; care burden; and shame. While not every participant simultaneously faced all four stressors, all were confronted with two or more. Each kind of stress was associated with a trigger for another. For the respondents, poverty was more than a lack of economic resources, it comprised multiple forms of stress that made life 'bitter and hopeless.' 


\section{The social construction of poverty among older adults}

Poverty is inevitably a social construction. The experience of poverty is thus shaped by social forces. Critical gerontology considers the experience of older adults in a context of structural arrangements, among which social policy is one of the most important parameters. Economic dependency and exclusion is not an unavoidable consequence of aging, but to some extent the result of conscious thought and action in the form of social policy (Walker, 2009). Some forms of resource distribution may lead to empowerment for some elders, but result in dependence and helplessness for others (Phillipson, 2009). Moreover, social policy reflects social norms that forge individuals' understanding of poverty, and in turn, shapes their attitudes towards people experiencing poverty. In this section, we try to understand the subjective experience of the aged poor in the context of China's anti-poverty policies.

As part of the Chinese economic reform, Dibao was adopted nationwide to tackle the 'New Urban Poverty' (Zhang, 2009) under the pursuit of a "harmonious socialist society” (Hu, 2005). In the same spirit, the Beijing municipal government introduced a set of anti-poverty measures to incorporate all older adults into a unified social security system by supporting those who had been excluded by pension and health plans designed for retirees.

Although these new measures showed determination of the government to tackle poverty, they appear to be inadequate to meet the needs of older adults in urban centres characterised by “welfare residualism” (Gao, Yoo, Yang \& Zhai, 2011). Echoing qualitative findings from other countries (Black \& Rubinstein, 2000; Lloyd-Sherlock \& Locke, 2008), this study suggests poverty means much more than material deprivation for older adults in the Chinese context. Their experiences are shaped within the family and community contexts. The multiple stressors of older adults experiencing poverty highlight three salient characteristics of China's current anti-poverty policies: a focus on economic support; assumptions about the role of 
family; and a commitment to wide coverage rather than to adequate provision.

\section{A focus on economic support}

While previous research on older adult poverty conventionally focused on material concerns (Lloyd-Sherlock \& Locke, 2008), this study presents the voice of older adults and identifies their perceived stress associated with poverty. We argue that any policies framed on a narrow conceptualisation of older adult poverty will not be sufficient to relieve such stress. China's anti-poverty policies seem to follow the logic of generally reducing the poverty rate by promoting mass purchasing power (Rojas, 2009), which resonates with the 'trickle-down' thesis of economic growth and poverty reduction. Although the goal of the Chinese government is to provide assistance responding to diverse needs of recipients, support for low-income older adults has been confined to providing cash benefits. Little attention has been given to the provision of necessary services and other support in-kind.

Policy measures designed to address income alone cannot resolve multiple vulnerabilities (Wang, Shang, \& Xu, 2011). The high incidence of poor health points to the need to tackle the inadequate provision of health care services, and the lack of community-based long-term care. The burden of care also suggests a need for better home-based care and support services. Mental health services are wanting, considering that the psychosocial consequences of poverty can conspire to undermine confidence, agency, and self-efficacy (Walker, 2014). When identifying elders in poverty, assessments should incorporate indicators reflecting other key stress dimensions, such as physical illness, care burden, mental health and the severity of social isolation.

While multiple services are required, they do not amount to a substitute for adequate material provision; resources must be sufficient to accord people the respect necessary to participate in society. Some policy progress has been made since our field study in 2010. For example, the recently revamped policy on Dibao in Beijing 
(Beijing Municipal Civil Affairs Bureau, 2014) provides that the income eligibility threshold for Dibao is conditionally lifted for families with members suffering from major illness or severe disability. It also provides that recipients over the age of 60 can receive a sum 20 per cent higher than the regular Dibao allowance. If the recipient has a major illness, his/her Dibao allowance is raised by 35 per cent, or by 30 per cent in the event of a severe disability. On a similar note, health policies targeting specific vulnerable populations have also raised their reimbursement rates and scope (Beijing Municipal Bureau of Human Resources and Social Security, 2014).

These policy amendments are commendable as policy makers have sown effort to differentiate the needs of elder recipients, accounting for certain health and care needs. Nevertheless, the magnitude of their effect is still to be observed in the face of the escalating cost of living in urban centres. There is cause for skepticism as similar amendments have not always yielded desired outcomes. For instance, one study conducted in Beijing indicated that the out-of-pocket payments for health care continues to represent a considerable financial strain on elders who do not have sufficient savings, especially for those who have multiple diseases and require daily medication (Bai, Qiao \& Xu, 2013). Economic support can be adequate only if benefits are set with a beneficiaries' actual needs in mind and attention given to the prevailing standard of living.

\section{Individual versus family}

Relationships with offspring were a crucial aspect of the experience of the elder participants. They can be as much a source of stress as of filial support. The care burden is largely related to the unfounded assumption that resources can and should be transferred from the young to the old. As in many societies, Chinese families are expected to offer the main protection against old age poverty. Policy has been designed so that these expectations will not be undermined, but reinforced (Izuhara, 2004). For example, entitlement to Dibao is determined on the basis of a family income accounting for married adult children, so as to enforce the filial obligation of 
adult children. Some of the respondents were denied Dibao assistance because of additional income of adult children. However, actually, the elders often received little financial support from their adult children. The presumption that adult children are always in a position to financially support their parents ignores the limited social mobility of some groups living in poverty.

In fact, elders often give more than they gain financially when pooling income with adult children, a phenomenon also reported in other developing countries (Barrientos, Gorman, \& Heslop, 2003; Lombard \& Kruger, 2009). Younger family members can claim disproportionately large shares of pooled incomes to meet their own needs (Lloyd-Sherlock, 2000). Apart from financial contribution, a number of the respondents provided intensive care to family members. Whereas $\mathrm{Li}, \mathrm{Xu}$, Chi, and Guo (2013) found that providing assistance to family members was associated with physical and psychological benefits for older adults, their findings were limited to household chores and care for grandchildren. In most instances in this study, caregiving was so stressful that the participants were depleted of their own time, health, and social life. While caring added to the risk of poor health, premature mortality and deep poverty (Vitaliano, Zhang, \& Scanlan 2003), the caregiving roles of older adults have not been taken into consideration by the current anti-poverty measures.

Policy measures seeking to address older adult poverty should be cautious about the conventional outlooks on household dynamics. Resource sharing and caregiving roles within the household should be considered and properly assessed on a case-by-case basis. Assistance in cash and in-kind, should be provided accordingly to older adults who care for their adult children, grandchildren and spouses. Institutionally, the Dibao eligibility needs to be revised to account for variations of households' financial and living arrangements to ensure that older adults are not overly burdened. 


\section{Emphasising coverage over security}

Shame is one of the psychosocial consequences of poverty and perceived social exclusion (Tomlinson, Walker, \& Williams, 2008). Individually, shame was expressed in terms of the respondents' low regard for self and in feelings of inferiority and worthlessness (Kaufman, 1996). The constant comparison between oneself and 'others' and the frequent perception of being despised showed that the experience of poverty is not only influenced by the family, but also by the broader community. Can social policy ameliorate dishonour brought about by hardship? Our study suggests that not only is tokenistic public support inadequate to substantively help older adults survive old age in dignity, or to share fully in community life, but they may exacerbate shame by inflicting a labelling effect on those who are low-income.

In China, realising full coverage of old-age social security and medical insurance has taken precedence over adequacy of provision (The State Council, 2011). As a result, although measures like the Welfare Pension intend to embrace older adults without other means, the level of provision is largely tokenistic. Similarly, while the OOOY medical insurance now offers some degree of protection against rising health care costs, the reimbursement rates remain inadequate for older adults with little or no savings. Some elders still chose not to see a doctor when ill. Moreover, while Dibao is aimed at 'covering whoever is eligible', its low income replacement rate means it is insufficient to protect people from multiple risks relating to a market economy (Gao et al. 2011). The meaningfulness of such policy measures was often questioned by the participants. As one put it, the reality runs contrary to government's outspoken commitment to 'providing a life with dignity'. Furthermore, our participants often compared themselves with peers who are not beneficiaries of Dibao and expressed a sense of inferiority. A monthly 200 Yuan pension is not received as a right, but perceived as a symbol of poverty. A policy in pursuit of coverage relying on means-tests and meagre benefits could hardly eliminate the sense of shame.

However, social policy is not solely responsible for the social construction of 
poverty. The multi-dimensional stress also reflected social development and social expectation. The stress from poor health lies in unaffordability of health and care service, which is a product of China's once radical privatisation of health care systems (Yip \& Hsiao, 2008). Contrasting with an investment incentive in child care, elder care is often viewed as death-delaying (Brennan, Cass, Himmelweit, \& Szebehely, 2012), and considered as "low-class" work (Hong, 2017). Furthermore, while older adults are frequently considered to be unproductive and a social burden as recipients of pensions and care (Tsien \& Ng, 2010), their contribution to their families through caregiving tends to be neglected.

Being poor is not inherently shameful. Moderation and frugality were once celebrated in China during the first 30 years of Communist rule. While the economic reform created continued high economic growth rates, the Gini coefficient, rising from 0.291 in 1981 (income based) to 0.421 in 2009 (consumption based) (the World Bank, 2013), highlights an expanding inequality. With marketisation and residualisation of welfare provision, social values have transformed. Being poor now constitutes a social failure in China (Yan, 2014). Today, more people in China blame poverty on laziness than in any other society except Taiwan, Puerto Rico, the Philippines and the United States (Walker, 2014). Despite the influence of social expectation and development, we may improve the life of older adults through manipulatable parameters, such as social policy.

\section{Conclusion}

This study, based on in-depth interviews conducted in one of China's largest cities, calls into question the assumption that current anti-poverty policies for urban older adults are effective. The multiple stressors experienced by the respondents were often attributable to their unique position in the life course. Their age, often combined with a history of poverty, meant that many suffer from poor health. Moreover, many assumed the responsibility of caring for younger generations. While traditional filial 
piety may require adult children to care for their parents, this can only happen if later generations have sufficient resources to share. Furthermore, while the ability to cope with hardship might once have been a virtue, this is no longer a socially upheld value. Indeed, older people felt ashamed of being poor.

The stress associated with poverty is partially a product of social policy. The current policies neglect the multi-dimensional needs of elder recipients, and offer limited, means-tested cash payments. When identifying older adults in need of support, income as an indicator should be complemented by other considerations, such as poor health, care burden, mental health and the severity of social isolation. The provision of cash assistance should be accordingly combined with service. Moreover, policy measures seeking to ameliorate older adult poverty should take into

account the actual resource sharing and caregiving roles of a household. Dibao eligibility must be reconsidered. However, it must be noted that poverty-related stress reflects social development and the expectations of a transitional society. This understanding provides us a broader context for situating the subjective experiences of the low-income elder population in urban China. Cost of daily living, poor health, multi-generational family responsibilities, and shame are not entirely unique to China's urban poor. The findings of this study may retain a broader relevance for many developing and middle-income countries where the lives of low-income older adults are shaped in similar ways.

\section{References}

Aldwin, C. M. (2007). Stress, coping, and development: An integrative perspective. New York: Guilford Press.

Atkinson, R. (1998). The life story interview. Thousand Oaks: Sage. 
Bai, R., Qiao, D. \& Xu, Y. (2013). The policy support on poor older adult in urban area: Case studies based on one community in Beijing. Beijing social science, (2), 120-126.

Barrientos, A. (2011). Social Protection and Poverty. International Journal of Social Welfare, 20(3), 240-249.

Barrientos, A., Gorman, M., \& Heslop, A. (2003). Old age poverty in developing countries: contributions and dependence in later life. World Development, 31(3), 555-570.

Beijing Municipal Civil Affairs Bureau (2014). Circular on regulating and coordinating the differentiated assistance of minimum living standard for urban and $\begin{array}{llll}\text { rural } & \text { residents } & \text { Bn } & \text { Beijing, }\end{array}$ http://bj.bendibao.com/zffw/20141226/175669.shtm.

Beijing Municipal Bureau of Human Resources and Social Security (2014). Circular on adjusting the funding standards for Basic Medical Insurance for urban residents in Beijing, retrieved from http://www.bjdch.gov.cn/n3952/n4060/c983911/content.html

Black, H. K., \& Rubinstein, R. L. (2000). Old souls: Aged women, poverty, and the experience of God. New Jersey: Transaction Publishers.

Brennan, D., Cass, B., Himmelweit, S., \& Szebehely, M. (2012). The marketisation of care: Rationales and consequences in Nordic and liberal care regimes. Journal of European Social Policy, 22(4), 377-391. doi: 10.1177/0958928712449772

Estes, C. L. (1979). The aging enterprise. San Francisco: Jossey-Bass.

Gao, Q., Yoo, J., Yang, S. M., \& Zhai, F. (2011). Welfare residualism: a comparative study of the Basic Livelihood Security systems in China and South Korea.

International Journal of Social Welfare, 20(2), 113-124.

Guan, X. (2003). Present Chinese urban poverty and antipoverty policy. Jiangsu Social Science, 2, 108-15. (in Chinese) 
Hong, L. (2017). Home care for older adults in China’s rural-urban dualism: Care workers’ fractured experiences. In S. Michel \& I. Peng (Eds.), Gender, Migration and the Work of Care: A Multi-Scalar Approach to the Pacific Rim. Palgrave Macmillan.

Hu J-t (2005) 'Speech in the Seminar of Enhancing the Capability of Constructing a Harmonious Socialist Society for Main Leaders and Cadres at the Provincial and Ministerial Level' [in Chinese] [http://news.xinhuanet.com/newscenter/2005-06/26/content_3138887.htm], accessed 03 March 2017.

Izuhara, M. (2004). Negotiating family support? The 'generational contract' between long-term care and inheritance. Journal of Social Policy, 33(4), 649-65.

Jones, F., Bright, J., \& Clow, A. (2001). Stress: Myth, theory, and research. New York: Pearson Education.

Kaufman, G. (1996). The psychology of shame: Theory and treatment of shame-based syndromes. New York: Springer Publishing Co.

Lazarus, R. S. (1991). Emotion and adaptation. New York: Oxford University Press.

Li, Y., Xu, L., Chi, I., \& Guo, P. (2013). Participation in productive activities and health outcomes among older adults in urban china. The Gerontologist, 54(5), 784-96. Lloyd-Sherlock, P. (2000). Old age and poverty in developing countries: New policy challenges. World Development, 28(12), 2157-68.

Lloyd-Sherlock, P., \& Locke, C. (2008). Vulnerable relations: lifecourse, wellbeing and social exclusion in Buenos Aires, Argentina. Ageing and Society, 28(06), 779-803.

Lombard, A., \& Kruger, E. (2009). Older persons: The case of South Africa. Ageing International, 34(3), 119-35. 
Morris, S., Sutton, M., \& Gravelle, H. (2005). Inequity and inequality in the use of health care in England: An empirical investigation. Social Science \& Medicine, 60: $1251-66$.

Neuman, W. L. (2005). Social research methods: Quantitative and qualitative approaches (Vol. 13). Boston: Allyn and Bacon.

Phillipson, C. (2009). Reconstructing theories of aging: The impact of globalization on critical gerontology. In V.L.Bengtson, D. Gans, N. M. Putney, \& M. Silverstein (Eds.), Handbook of theories of aging (pp.615-628). New York: Springer.

Qiao, X., Zhang, K., \& Sun, L. (2006). Zhong guo lao nian ren kou te zheng fen xi. Population Journal, 4, 3-8. (in Chinese)

Rojas, M. (2009). Enhancing poverty-abatement programs: A subjective well-being contribution. Applied Research in Quality of Life, 4(2), 179-99.

Rowntree, B. S. (1901). Poverty: A study of town life. Macmillan.

Saunders, P., \& Sun, L. (2006). Poverty and hardship among the aged in urban China. Social Policy \& Administration, 40(2), 138-57.

Schröder-Butterfill, E. (2004). Inter-generational family support provided by older people in Indonesia. Ageing and Society, 24(4), 497-530.

Sen, A. (1981). Poverty and famines: an essay on entitlement and deprivation. Oxford university press.

Streeten, P. (1981). First things first: Meeting the basic human needs in developing countries. New York: Oxford University Press.

The State Council of P.R. China. (2011). Guidance of the State Council on the development of urban residents social old-age insurance pilot. Retrieved from http://www.gov.cn/zwgk/2011-06/13/content_1882801.htm.

Tomlinson, M., Walker, R., \& Williams, G. (2008). Measuring poverty in Britain as a multi-dimensional concept, 1991 to 2003. Journal of Social Policy, 37(4), 597-620. 
Townsend, P. (1979). Poverty in the United Kingdom: a survey of household resources and standards of living. Univ of California Press.

Tsien, T. B., \& Ng, G. T. (2010). Older adults as caregivers in Hong Kong. China Journal of Social Work, 3(2-3), 231-45.

Vera-Sanso, P. (2012). Gender, poverty and old-age livelihoods in urban South India in an era of globalisation. Oxford Development Studies, 40(3), 324-340.

Vitaliano, P. P., Zhang, J., \& Scanlan, J. M. (2003). Is caregiving hazardous to one's physical health? A meta-analysis. Psychological Bulletin, 129(6), 946.

Walker, A. (2009). Aging and social policy: Theorizing the social. In V.L.Bengtson, D. Gans, N. M. Putney, \& M. Silverstein (Eds.), Handbook of theories of aging (pp. 595-614). New York: Springer.

Walker, R. (2014). The shame of poverty. Oxford: Oxford University Press.

Wang, Z. (2010). Determinant factors of China's rural old age impoverished female: An application of Cox proportion risk model. Chinese Journal of Population Science, 1, 75-83. (In Chinese)

Wang, X., Shang, X., \& Xu, L. (2011). Subjective well - being poverty of the older adult population in China. Social Policy \& Administration, 45(6), 714-31.

Wilensky, HL, \& Lebeaux, CN. (1965). Industrial society and social welfare. New York: The Free Press.

World Bank (2013) 'Poverty and Inequality Database' [http://databank.worldbank. org/data/home.aspx], accessed 17 June 2013.

Xie, E. (2011). Income-related inequalities of health and health care utilization. Frontiers of Economics in China, 6(1), 131-56.

Yan, M. (2014). New urban poverty and new welfare provision: China's Dibao system. In Gubrium, E.K., Pellissery, S. \& Lødemel, I. (Eds.) The Shame of It: Global Perspectives on Anti-Poverty Policies, 17-36. 
Yip, W. \& Hsiao, W. C. (2008). The Chinese Health System At A Crossroads: A new infusion of government funds has sparked debate in China about how best to transform money into effective services. Health affairs, 27(2), 460-468.

Zhang, H. (2009). Poverty and politics the evolution of minimum living standard guarantee system in china in the period of transition. Asia Pacific Journal of Social Work and Development, 19(2), 5-20. 
Table 1. Policy measures against urban old age poverty.

\begin{tabular}{|c|c|c|c|}
\hline Policy measures & $\begin{array}{l}\text { Starting } \\
\text { year }\end{array}$ & Targeting & Contents \\
\hline Dibao & 1999 & $\begin{array}{l}\text { Household income per capita of urban citizens holding } \\
\text { non-agricultural registered } \\
\text { residence lower than the urban citizen minimum living } \\
\text { standard of the local city }\end{array}$ & $\begin{array}{l}430 \text { Yuan per capita per month in } 2009 \\
710 \text { Yuan per capita per month in } 2015\end{array}$ \\
\hline The welfare pension & 2008 & People aged $60+$ without any social security & $\begin{array}{l}200 \text { Yuan per capita per month in } 2008 \\
385 \text { Yuan per capita per month in } 2015\end{array}$ \\
\hline $\begin{array}{l}\text { One-Old-One-Young' } \\
\text { serious illness medical } \\
\text { insurance }\end{array}$ & 2007 & $\begin{array}{l}\text { (1)Residents aged } 60+\text { with non-agricultural Hukou and } \\
\text { not included in Urban } \\
\text { Employee Basic Medical Insurance (UEBMI); and female } \\
\text { residents aged } 50+\text { with } \\
\text { non-agricultural Hukou and not included in UEBMI } \\
\text { (2)Recipients of Dibao in Beijing } \\
\text { (3)Recipients of urban citizen hard living allowance of } \\
\text { Beijing } \\
\text { (4)Early retirement staff who received medical benefits with } \\
\text { reference to medical } \\
\text { assistance for hard living urban residents }\end{array}$ & $\begin{array}{l}\text { Beijing urban elderly medical insurance financing } \\
\text { for } 1400 \text { yuan per person per year, of which the } \\
\text { elderly individual pays } 300 \text { yuan, the remaining } \\
1100 \text { yuan from the financial subsidies. When the } \\
\text { medical expense of older residents who have no } \\
\text { medical insurance exceeds } 1300 \text { Yuan, } 60 \% \text { of the } \\
\text { remaining expense can be reimbursed. The maximum } \\
\text { cumulative reimbursement for a medical } \\
\text { year is } 70,000 \text { Yuan }\end{array}$ \\
\hline
\end{tabular}




\begin{tabular}{|c|c|c|c|}
\hline & & $\begin{array}{l}\text { (5)Retired activists of the community committee who } \\
\text { received medical benefits with } \\
\text { reference to medical assistance for hard living urban } \\
\text { residents }\end{array}$ & \\
\hline Home care allowance & 2008 & $\begin{array}{l}\text { Older residents with Beijing Hukou and aged } 60+\text { who } \\
\text { were the oldest, or had a } \\
\text { low-income, or living alone or living with their older spouses }\end{array}$ & $\begin{array}{l}\text { Home care allowance of } 50-250 \text { Yuan per person a } \\
\text { month. The subsidies were used to purchase home } \\
\text { care services or to offset nursing home fees }\end{array}$ \\
\hline
\end{tabular}


Table 2. Age, health condition and medical history of participants.

\begin{tabular}{|l|l|}
\hline Characteristics & $(N=17)$ \\
\hline Age - & \\
$60-65$ & 5 \\
$66-69$ & 3 \\
$70-75$ & 4 \\
$76-79$ & 1 \\
$80-85$ & 4 \\
Health conditiona & - \\
Advanced cancer & 1 \\
E ye problem (e.g. cataract, lesion) & 3 \\
Cardiovascular disease & 8 \\
Cervical spondylosis & 3 \\
Diabetes & 1 \\
Serious leg pain & 4 \\
Arthritis & 2 \\
Fracture & 1 \\
Urinary incontinence & \\
Tracheitis & 2 \\
Medical history & \\
Tumour surgery & \\
Thoracic spinal surgery & \\
Facial surgery & \\
Hospitalisation for cardiovascular disease & \\
No hospitalisation record & \\
& 2 \\
\hline
\end{tabular}

